\title{
El enfoque dialógico de la argumentación y la polifonía, puntos de vista evidenciales y puntos de vista alusivos
}

\section{Dialogical Approach to Argumentation and Polyphony, Evidential Points of View and Allusive Points of View}

\author{
María Marta García Negroni \\ Investigadora Principal, CONICET \\ Profesora asociada, Departamento de Humanidades \\ Universidad de San Andrés \\ Vito Dumas 284. Victoria, Provincia de Buenos Aires B1644BID. Argentina \\ mgarcianegroni@udesa.edu.ar \\ Orcid ID 0000-0001-7204-6575
}

Resumen: En el marco del Enfoque dialógico de la argumentación y la polifonía, este trabajo propone una caracterización de los puntos de vista evidenciales y de los puntos de vista alusivos. Si bien ambos permiten poner de manifiesto el carácter dialógico de toda enunciación, la presencia de unos y otros determina modos distintos de inscripción del enunciado en la cadena discursiva, lo que a su vez repercute en la construcción del sentido y de la (inter)subjetividad. En efecto, mientras que los evidenciales exigen la identificación de un marco de discurso previo que se muestra como la causa de la enunciación y frente al cual queda constituido el posicionamiento subjetivo de respuesta manifestado en el enunciado, los alusivos evocan, mediante diferentes tipos de procedimientos, discursos "otros" que deben ser recuperados en el interdiscurso como parte de la "memoria discursiva" y, al hacerlo, no solo indican un cierto posicionamiento subjetivo sino que además permiten entretejer lazos de complicidad intersubjetiva.

Palabras clave: Dialogismo. Polifonía. Argumentación. Puntos de vista evidenciales. Puntos de vista alusivos.
Abstract: In the framework of the Dialogical Approach to Argumentation and Polyphony, this paper analyzes evidential and allusive points of view. While both reveal the dialogical character of all enunciation, their presence determines different ways of inscribing the utterance in the discursive chain, which in turn affects the construction of meaning and (inter)subjectivity. In fact, while the evidential points of view involve the identification of a previous discourse frame that is shown as the cause of the enunciation and that explains the subjective positioning of response manifested in the utterance, the allusive ones evoke, through different types of procedures, "other" discourses that must be recognized in the interdiscourse as part of the "discursive memory" and, in so doing, not only indicate a certain subjective positioning but also weave ties of intersubjective complicity.

Keywords: Dialogism. Polyphony. Argumentation. Evidential Points of View. Allusive Points of View. 


\section{INTRODUCCIÓN}

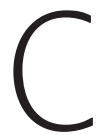

omo es sabido, las teorías pragmáticas de influencia anglosajona descomponen el significado en un elemento objetivo (i.e., el contenido proposicional) y un elemento subjetivo (i. e., la fuerza ilocucionaria). Al mismo tiempo, incluyen como parte de la descripción semántica la categoría de sujeto hablante, cuyas intenciones comunicativas, siempre conscientes y voluntarias, se reflejarían en el sentido, el que, por su parte, sería recuperado de modo transparente y sin conflicto por el interpretante. A diferencia de estas perspectivas, y en la senda trazada por las teorías de la polifonía (Ducrot 1984), del dialogismo (Bajtín) y de la argumentación lingüística (Ducrot 2004; Carel/Ducrot), el Enfoque dialógico de la argumentación y de la polifonía, en el que se sustenta mi investigación, busca profundizar en la construcción de una teoría no veritativista y no referencialista de la significación, no unicista ni intencionalista del sujeto y centrada en el funcionamiento de los signos en la lengua y en el discurso.

Con el fin de avanzar en esta línea investigativa, en este trabajo me detendré en el estudio de un tipo particular de puntos de vista (de aquí en más Pdv) que pueden expresarse a través de la enunciación -los Pdv evidenciales y los PdV alusivos- y en cómo ellos contribuyen al sentido del discurso y a la configuración dialógica de la (inter)subjetividad. Mi objetivo será pues doble. Por un lado, intentaré demostrar que los Pdv evidenciales obligan a identificar la causa de la enunciación en la que ellos se expresan en un marco de discurso mostrado y previo al que la enunciación responde dialógicamente a través de un cierto posicionamiento subjetivo. La caracterización de los Pdv evidenciales así como de su relación dialógica con los distintos marcos de discurso previos que ellos instan a recuperar aspira a contribuir a los estudios sobre evidencialidad al poner de manifiesto los lazos semánticos que existen entre esos significados y los distintos modos en los que queda representada la causa de la enunciación. Por otro lado, buscaré demostrar que, íntimamente vinculados con lo que Authier-Revuz (1984) caracteriza como formas de la heterogeneidad mostrada no marcada, los PdV alusivos evocan discursos "otros" que deben ser recuperados en el interdiscurso como parte de la "memoria discursiva" (Courtine) y que, al hacerlo, indican un determinado posicionamiento subjetivo al tiempo que entretejen lazos de complicidad intersubjetiva.

$\mathrm{El}$ artículo se organiza como sigue. En primer lugar $(\$ 2)$, introduzco el marco teórico-metodológico del Enfoque dialógico de la argumentación y de la polifonía: tributario de las teorías de la polifonía, de la argumentación lingüística y del dialogismo, este enfoque busca explicar los aspectos polifónico-argu- 
mentativos del sentido en clave dialógica y formalizar las relaciones dialógicas en clave argumentativa. En la sección siguiente $(\$ 3)$, me refiero a los Pdv evidenciales y a las instrucciones dialógico-causales que contienen. Luego, propongo una caracterización de los Pdv alusivos y doy cuenta de algunos de los procedimientos que permiten identificarlos $(\$ 4)$. Por último, en $(\$ 5)$, presento las conclusiones del estudio.

\section{El ENFOQUE DIALÓGICO DE LA ARGUMENTACIÓN Y LA POLIFONÍA}

En términos generales y asociada al nombre de Ducrot, la teoría de la polifonía describe la presencia en el enunciado de una multiplicidad de voces o Pdv que no necesariamente deben ser atribuidos a su autor. Esa polifonía se manifiesta, entre otros, en los casos de doble enunciación, en la presuposición y la nominalización, en los enunciados negativos, en los enunciados irónicos. De gran alcance descriptivo y poder explicativo a nivel del enunciado, la teoría polifónica cuestiona, así, el postulado de la unicidad del sujeto hablante, según el cual para un enunciado hay un único sujeto, es decir un único individuo que es, a la vez, el responsable de las actividades psicofisiológicas de las que depende la producción del enunciado y el responsable de todo cuanto en él se comunica. Contrariamente a esta visión, la polifonía sostiene que el sujeto hablante es exterior al sentido y que, en cambio, resulta ineludible distinguir dos figuras discursivas: la de locutor y la de enunciador. Dentro de la categoría de locutor, Ducrot distingue el locutor en tanto tal (de aquí en más L) del locutor en tanto ser del mundo (de aquí en más $\lambda$ ). El primero (L) es el responsable de la enunciación según el enunciado, i.e., el locutor considerado únicamente en su compromiso enunciativo. El segundo $(\lambda)$ es, en cambio, aquel a quien remiten las marcas de primera persona y de quien se habla en el enunciado que contiene dichas marcas. El autor ilustra la diferencia entre estas dos imágenes del locutor en relación con el problema de los performativos explícitos. Así, respecto de la fórmula je soubaite (deseo), Ducrot $(1984,202)$ explica:

no es en tanto locutor que se experimenta el deseo, sino en tanto ser del mundo, independientemente de la aserción que se hace de él. En cambio, el acto de deseo, que no existe más que en el habla en la que se realiza, pertenece típicamente a L: L realiza el acto de deseo asertando que $\lambda$ desea. ${ }^{1}$

1. La traducción de las citas aquí incluidas es siempre mía. 
Los enunciadores, por su parte, representan los distintos Pdv que se manifiestan en el enunciado y con los que L no necesariamente queda identificado. En palabras de Ducrot $(1984,208)$,

El locutor L habla en el sentido en el que el narrador cuenta, es decir que es presentado como la fuente de un discurso. Pero las actitudes expresadas en ese discurso pueden ser atribuidas a enunciadores de los que se distancia, del mismo modo en que los puntos de vista manifestados en el relato puede ser los de sujetos de conciencia extraños al narrador.

Según la concepción polifónica, el sentido nace así de la superposición de los diversos PdV que se expresan en la enunciación y de la actitud (identificación, distanciamiento, rechazo, etc.) que L adopta frente a ellos. Señalo, asimismo, que en términos de la semántica argumentativa esos Pdv se presentan bajo la forma de encadenamientos argumentativos, ya normativos, ya transgresivos (Ducrot 2004; Carel/Ducrot). En el primer caso, el encadenamiento aparece articulado por conectores conclusivos del tipo de por lo tanto (abreviado $P L T$ ); en el segundo, por conectores concesivos del tipo de sin embargo (abreviado $S E)$.

De acuerdo con estos lineamientos, el Enfoque dialógico de la argumentación y de la polifonía (de aquí en más, EDAP) considera que la lengua es fundamentalmente polifónica y argumentativa, por lo que mantiene el principio según el cual "el sentido de una entidad lingüística no es nada más que un conjunto de discursos que esa entidad evoca" (Ducrot (2004, 364). Al mismo tiempo asume que los diversos Pdv que se expresan a través de la enunciación no tienen por qué ser atribuidos a un mismo y único sujeto que, consciente y voluntariamente, los pondría en escena.

Ahora bien, si la semántica ducrotiana contempla la puesta en escena de una multiplicidad de PdV y define el sentido en términos de encadenamientos discursivos evocados, su foco no está puesto en la inserción de los enunciados en la red interdiscursiva, ni en cómo esa inserción repercute en la construcción del sentido y de la (inter)subjetividad. Desde la perspectiva del EDAP, en cambio, dicha puesta en foco resulta necesaria para explicar, entre otros, los efectos de sentido que surgen de la presencia de los Pdv que plasman significados evidenciales y de los PdV que vehiculizan alusiones al interdiscurso. Por ello, el EDAP propone incorporar como parte de la descripción semántica los aspectos dialógicos del sentido, que se relacionan con la inclusión del enunciado en la cadena discursiva. Como se recordará, 
el concepto de dialogismo refiere a los vínculos que todo enunciado mantiene con los producidos anteriormente así como con los potenciales enunciados futuros que puedan llegar a aparecer en respuesta a él (Bajtín 28185). De este modo, toda palabra viva (i. e., la empleada en el discurso) supone una articulación con palabras previas o posteriores, reales o imaginarias, e inscribe en sí misma una posición subjetiva definida por su relación con la alteridad.

En suma, fuertemente inspirado en los presupuestos epistemológicos de las teorías de la polifonía, la argumentación y el dialogismo, el EDAP plantea la necesidad de incluir en la descripción polifónico-argumentativa la caracterización de aquellos PdV que hacen ver la enunciación como respuesta siempre dialógica frente a discursos previos o prefigurados o como rememoración de discursos "otros". El EDAP busca dar cuenta así de los elementos de sentido relacionados tanto con la inscripción del enunciado en la cadena del discurso como con el consecuente posicionamiento subjetivo de respuesta o de anticipación que en él queda configurado.

En lo que sigue, y en el marco de esta propuesta de caracterización del sentido en términos de discursos argumentativos evocados de manera dialógico-polifónica, presento un análisis de los Pdv evidenciales y de los Pdv alusivos. Como adelanté, buscaré mostrar que mientras que los primeros contienen instrucciones dialógico-causales que obligan a recuperar marcos de discurso previos o previstos que se muestran como la causa de (parte de) la enunciación en la que esos PdV se expresan, la ocurrencia de los segundos, al rememorar dialógicamente lo "ya dicho" en el interdiscurso, revelan la presencia no marcada del discurso del otro y permiten establecer un lazo de complicidad con el destinatario que reconoce esas huellas como parte de la "memoria discursiva".

\section{EL EDAP Y LOS PdV EVIDENCIALES}

Como se sabe, la evidencialidad suele definirse como el dominio semántico relacionado con la indicación de la fuente u origen de la información que el hablante comunica en su enunciado (Aikhenvald). Se afirma que dicha fuente es directa cuando el conocimiento de lo que hablante dice ha sido adquirido por medio de una percepción originada en alguno de sus sentidos, e indirecta cuando el conocimiento de lo que se afirma procede ya de una inferencia, ya de la cita de un discurso ajeno (Willett). 
Existen lenguas (tal el caso, por ejemplo, del quechua) en las que la fuente del conocimiento del hablante está codificada de manera obligatoria en la gramática: distintos morfemas verbales especifican si el hablante fue testigo directo de los hechos que narra, si los infirió o si oyó acerca de ellos por boca de terceros. Pero también existen lenguas que, aunque no tienen gramaticalizada la evidencialidad, disponen de ciertos recursos que permiten el despliegue, en ciertos contextos específicos, de "estrategias evidenciales" (Aikhenvald). A este segundo grupo pertenece, entre otras, el español. En efecto, en esta lengua, algunos empleos específicos del modo, del tiempo y del aspecto verbal, determinadas estructuras sintácticas, ciertas construcciones adverbiales, algunos marcadores del discurso, etc. pueden manifestar este tipo de significados y pueden, por lo tanto, describirse como pertenecientes a alguno de los subdominios en los que se ha clasificado la evidencialidad en las lenguas que sí la gramaticalizan (ver Bermúdez 2005, 2016; Cornillie 2007, 2016; Escandell Vidal; Leonetti/Escandell Vidal; Reyes; Rodríguez Ramalle, entre otros). Así, por ejemplo, las locuciones conjuntivas así que, conque, de manera que, constituyen, según Rodríguez Ramalle (239), marcas evidenciales

pues la causa de la que parten, si bien no necesita estar establecida necesariamente en el contexto, siempre aparece fijada en la fuente u origen de los conocimientos que posee el hablante: lo que ha oído, lo que ve, lo que le han dicho, lo que conoce porque forma parte de su acervo cultural. (El destacado es mío)

En línea con Rodríguez Ramalle, sostengo que las marcas de la evidencialidad perceptiva, inferida o transmitida que se manifiestan en el enunciado se presentan como causadas por algo que debe descubrirse para poder acceder al sentido. Pero dado que, desde la perspectiva que adopto, de lo que se trata es de "dar cuenta de aquello que, según el enunciado, el habla hace" (Ducrot 1984, 174), buscaré mostrar que ese algo no debe caracterizarse en términos de elementos exteriores y preexistentes al discurso (las fuentes empíricas de la información del hablante), sino bajo la forma de discursos argumentativos evocados en los que una cierta representación discursiva de esas fuentes queda articulada normativa o transgresivamente con aserciones sobre $\lambda$ respecto de ellas. ${ }^{2}$

2, Recuerdo que $\lambda$ corresponde al locutor en tanto ser del mundo, es decir aquel a quien remiten las marcas de primera persona y de quien se habla en el enunciado que contiene dichas marcas. 
Dicho de otro modo, son estos discursos argumentativos o marcos de discurso previos los que, en el sentido del enunciado con Pdv evidenciales, se presentan como la causa de la enunciación. Más específicamente, en el caso de los Pdv evidenciales directos, propongo que sus instrucciones dialógico-causales ${ }^{3}$ instan a identificar y recuperar la causa de la enunciación en un marco de discurso previo que, referido a un registro perceptual de $\lambda$ (por ej., Fui testigo perceptual de $x$ por lo tanto puedo dar fe de X), autentifica el decir de L. En el caso de los PdV evidenciales indirectos, la causa de la enunciación de L debe hallarse ya sea en marcos de discurso conjeturales de $\lambda$ (por ej., Veo/Dicen $X(b)$ por lo tanto infiero $X(a)$ ), ya sea en marcos en los que quedan establecidas distintas relaciones entre $\lambda$ y los discursos citados o evocados (Dicen/dijeron $X$ sin embargo no puedo confirmar $X$ / Dicen/dijeron $X$ por lo tanto admito que X es posible / Dijiste X sin embargo veo que no $X /$ Dicen/dijeron $X$ sin embargo $X$ no es así para mí, entre otros posibles).
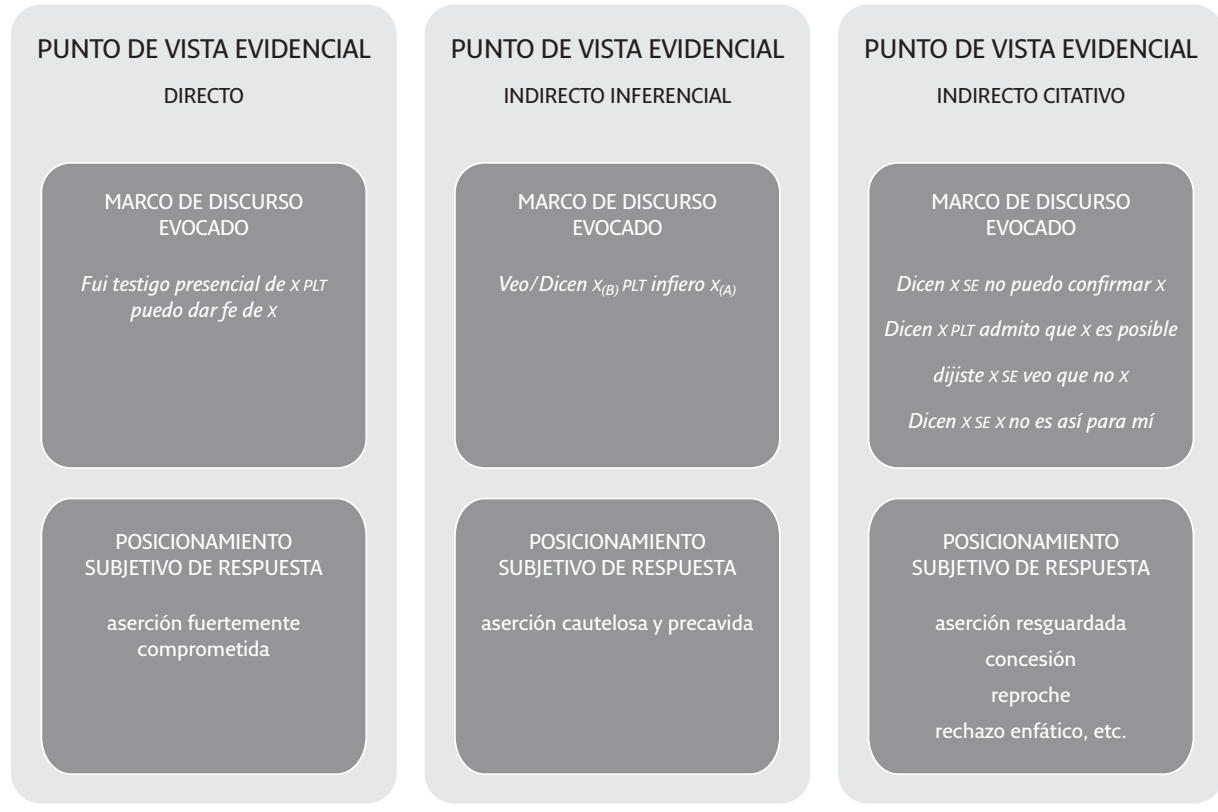

Tabla 1. Pdv evidenciales directos e indirectos

3. Junto con las instrucciones polifónicas, ilocucionarias y argumentativas, las causales (i.e., la cualificación del habla por su causa) permiten dar cuenta del sentido del enunciado, es decir de la representación que el enunciado brinda de su propia enunciación (Ducrot 1984). 
Por otra parte, y al igual que en el caso de los Pdv descritos por la teoría polifónica, la ocurrencia de los evidenciales determina posicionamientos diversos por parte de L. Pero, aquí, esos posicionamientos deben ser interpretados como la indicación de la respuesta dialógica a los marcos de discurso sobre los que se funda la enunciación. Así, si el Pdv evidencial es directo, el posicionamiento subjetivo de respuesta quedará plasmado en una enunciación fuertemente asertiva; si es indirecto, en cambio, la enunciación podrá revestir las formas de una aserción precavida y cautelosa, de una concesión momentánea, de un reproche, de un rechazo enfático, etc. según el marco de discurso evocado al que la enunciación responda (García Negroni 2016a y 2016b; García Negroni/Libenson).

Para intentar dar cuenta de cómo los Pdv evidenciales plasmados en el enunciado contribuyen a la representación dialógica y polifónico-argumentativa que el enunciado brinda de su propia enunciación, propongo considerar, a modo de ilustración, los siguientes fragmentos: ${ }^{4}$

1. "Lo encontré bien, batallando" [Titular]

La Presidenta visitó por unos 40 minutos a Alfonsín, que se repone de una intervención quirúrgica. (Página/12, 13 agosto 2008)

2. Capitanich justificó la ausencia de Boudou en el Senado: "Debe haber sido porque tuvo otras cosas en agenda” [Titular] (Clarín 11 julio 2014)

3. La suba en el precio de los servicios habría originado el aumento de expensas impagas [Titular]

Según la Cámara de Administradores de Consorcios la mayoría de los inquilinos y propietarios que tienen deuda no pueden hacer frente a todas las erogaciones y para no sufrir cortes de luz o gas prefieren pagar las expensas "cuando pueden". (El Día 28 marzo 2017)

4. No seré feliz, pero tengo marido (Título de una obra de teatro de Viviana Gómez Torpe)

Como puede constatarse, forma parte de la interpretación de (1) que se reconozca que su enunciación se presenta a sí misma como causada (i. e., surgida en respuesta) y autentificada por una cierta representación discursiva del registro perceptivo de $\lambda$ de una determinada situación. Y esto en la medida en

4. Las itálicas en los fragmentos que ejemplifican este trabajo son siempre mías. 
que el Pdv evidencial directo desplegado por la estructura sintáctica encontrar $+O D+$ predicativo objetivo hace de los discursos acerca de la percepción directa de algo por parte de $\lambda$-aquí, aquellos relativos al estado de salud percibido visualmente por la entonces presidenta Kirchner en el expresidente Alfonsín, tal como queda explicitado luego en el texto- la prueba fundante de la enunciación global:

[Fui $(\lambda)$ testigo perceptual de $\mathrm{X}_{\text {(intervención reciente SE buen estado de salud) }}$ PLT puedo $(\lambda)$ dar fe de $\mathrm{X}]$

Es precisamente este marco de discurso (que represento entre corchetes) evocado por el Pdv evidencial directo el que explica el posicionamiento de alto compromiso enunciativo de $\mathrm{L}$ en (1):

[como puedo dar fe de lo que digo (porque lo vi)], afirmo con certeza que lo encontré bien y batallando.

De hecho, (1) no admitiría como posibles continuaciones "pero yo no lo vi" o "pero no puedo garantizarlo". En otras palabras, la enunciación asertiva y comprometida de L en (1) queda justificada como respuesta dialógica a la presencia mostrada del marco de discurso que la desencadena. Represento la articulación entre el marco de discurso causante de la enunciación y el posicionamiento subjetivo de respuesta mediante el conector dialógico POR LO TANTO:

[Fui $(\lambda)$ testigo perceptual de X PLT puedo $(\lambda)$ dar fe de $\mathrm{X}$ ] POR LO TANTO enunciación asertiva comprometida de $\mathrm{L}$

Por su parte, en (2), que constituye un caso de doble enunciación (Ducrot 1984, 193), ${ }^{5}$ la presencia del PdV evidencial inferencial manifestado por la perífrasis deber+infinitivo en el discurso referido de $\mathrm{L}_{2}$ exige interpretar esa enunciación como causada por un marco de discurso previo del tipo,

[Se sabe $\mathrm{X}_{\mathrm{B}}$ (NEG. presidir el Senado) PLT infiero $\left(\lambda_{2}\right) \mathrm{X}_{\mathrm{A}}$ (tener otras cosas en agenda)] es decir, como basada en una abducción de $\lambda_{2}$ a partir de un indicio, ${ }^{6}$ en este caso el relativo a la ausencia del entonces vicepresidente Boudou en la sesión

5. Como indica Ducrot, en estos casos, el sentido del enunciado atribuye la enunciación a dos locutores distintos $\left(\mathrm{L}_{1}\right.$ y $\left.\mathrm{L}_{2}\right)$. En (2), $\mathrm{L}_{1}$ queda homologado con el responsable de la enunciación periodística y $\mathrm{L}_{2}$, con Capitanich.

6. Para un estudio de la abducción en el marco de la teoría de los bloques semánticos, ver Carel. 
del Senado. El posicionamiento subjetivo de respuesta (la enunciación cautelosa y precavida de $\mathrm{L}_{2}$ ) que queda configurado constituye así la huella de la respuesta dialógica a ese marco de discurso sobre el que se funda la enunciación:?

[como estoy infiriendo que tenía otras cosas en agenda (a partir de su ausencia en el Senado)], afirmo precavidamente que debia tener otras cosas en agenda.

Y como esta enunciación prudente y cautelosa se presenta como surgida de una abducción de $\lambda_{2}$, ese ser "que supuestamente existe fuera del discurso pero que solo es localizable por su rol de L en el interior del discurso" (Ducrot 1984, 232), se explica por qué el discurso de $\mathrm{L}_{2}$ en (2) no podría aparecer seguido por "pero yo no lo creo", sin que se produjera una incoherencia. ${ }^{8}$

[Se sabe $\mathrm{X}_{\mathrm{B}}$ PLT infiero $\left(\lambda_{2}\right) \mathrm{X}_{\mathrm{A}}$ ] POR LO TANTO enunciación cautelosa y precavida de $\mathrm{L}$

En (3), en cambio, la ocurrencia del Pdv evidencial desplegado por el llamado condicional periodístico o de rumor (NGLE) babría originado en el titular de la nota periodística insta a ver la enunciación como suscitada por un marco de discurso citativo, que en este caso es del tipo

[Dicen X (aumento de servicios PLT aumento expensas impagas) SE no puedo $(\lambda)$ confir$\operatorname{mar} \mathrm{x}]$

Este elemento de sentido (i.e., esos discursos argumentativos previos atribuidos, tal como se indica luego en el texto, a la Cámara de Administradores de

7. Entre otros, Kasim y Cornillie han analizado la perífrasis deber + infinitivo en el marco de los estudios de evidencialidad. Para una caracterización como marcador evidencial inferencial del verbo epistémico francés devoir, ver Dendale y Dendale/Coltier.

8. Para Cornillie (2016), la imposibilidad de la combinación del auxiliar evidencial deber (marcador de razonamiento inductivo del hablante) con "pero yo no lo veo así" muestra que es imposible disociar la fuente de la información del hablante.

9. Característico de los medios de comunicación, este empleo del condicional ha sido objeto de numerosos estudios. Reyes (33) lo analiza como evidencial citativo. Análogamente, Vatrican caracteriza al condicional de rumor o periodístico como evidencial "porque da a entender que el hablante cita, esto es, reproduce lo que alguien le ha dicho, sin asegurar que sea verdad" (264). Para Kronning (2015), el condicional epistémico de atribución "es un marcador gramatical mixto, que expresa a un tiempo la modalización cero-que indica la negativa del hablante a hacerse cargo del contenido cognitivo de su enunciado- y un tipo particular de mediación epistémica (o evidencialidad), a saber: la atribución de dicho contenido a una fuente externa" (507-08). Bermúdez (2016), por su parte, describe el condicional de rumor (al que distingue del condicional científico) como marcador de información de tercera mano ("alguien dice que alguien dice [que alguien dice...] X"). 
Consorcios, pero que $\lambda$ no puede confirmar) explica la actitud de precaución epistemológica de L, que no hace del decir rememorado el objeto declarado de su propia enunciación:

[como no puedo confirmar (eso que dicen)], afirmo con reservas que la suba en el precio babría originado el aumento de las expensas impagas.

En otras palabras, en (3) y por las instrucciones dialógico-causales asociadas al $\mathrm{PdV}$ evidencial, la imagen que brinda el enunciado de su propia enunciación es la de un habla causada por un decir ajeno que L (el responsable de la enunciación periodística) no asume por su cuenta porque $\lambda$ (el individuo que era y que es fuera de su enunciación) no tiene las pruebas para garantizarlo. Y es esta calificación de la enunciación por su causa, que forma parte del sentido del enunciado, la que da cuenta de la enunciación resguardada y precavida que se manifiesta en (3). Como bien señala Vatrican, en relación con la modalidad epistémica, el condicional de rumor o periodístico "funciona como operador epistémico que no opera sobre el enunciado -como en el caso del condicional de conjetura- sino sobre la enunciación” (266).

[Dicen X SE X no puedo $(\lambda)$ confirmar X] POR LO TANTO enunciación resguardada de $\mathrm{L}$

Diferente sería el caso si, en lugar de habría originado, apareciera el pretérito perfecto simple de indicativo, el que, al no vehiculizar un Pdv evidencial, no contiene instrucciones que exijan identificar un marco de discurso previo como la causa de la enunciación.

5. La suba en el precio de los servicios originó el aumento de expensas impagas.

En efecto, presentada por originó como motivada por una decisión propia del sujeto que elegiría comunicar esa información a propósito de la situación (Ducrot 1984, 186), la imagen de la enunciación que propone (5) es la de un L que se hace garante del PdV relativo a la relación causal entre aumento de servicios y no pago de expensas y con el que, por lo tanto, queda fuertemente comprometido. De hecho, si luego de la enunciación de estos enunciados, se determinara que tal relación no era cierta, solo al autor de (5) -y no al de (3)- podría reprochársele el haber mentido, inventado o inducido a error.

Se observará, no obstante, que si la enunciación de (3) es resguardada, ello no impide que el enunciado argumente en el mismo sentido que (5): tan- 
to (3) como (5) podrían tener como posibles continuidades discursivas El gobierno debe revisar su política de tarifas (que encadena sobre el primer segmento) o Los administradores de los consorcios están preocupados (que encadena sobre el segundo segmento). Como observa Kronning (2012, 87), "el CE [condicional epistémico] [...] tiene una orientación modal invariablemente positiva". ${ }^{10}$

6. La suba en el precio de los servicios originól habría originado el aumento de expensas impagas, por lo que el gobierno debe revisar su política de tarifas.

7. La suba en el precio de los servicios originó/habría originado el aumento de expensas impagas, por lo que los administradores de los consorcios están preocupados.

Sin embargo, ha de verse que la presencia del Pdv evidencial en (3) restringe en parte la significación de la oración base (5): a diferencia de (5), (3) no evoca (i. e., no admite como su prolongación) discursos del tipo En efecto, la política tarifaria del gobierno impactó fuertemente en los bolsillos de propietarios e inquilinos.

8. La suba en el precio de los servicios originó el aumento de expensas impagas. En efecto, la política tarifaria del gobierno impactó fuertemente en los bolsillos de propietarios e inquilinos.

9. *La suba en el precio de los servicios habría originado el aumento de expensas impagas. En efecto, la política tarifaria del gobierno impactó fuertemente en los bolsillos de propietarios e inquilinos.

Tal como se observa en (8), tal continuación es posible para (5), pues ella constituye una reformulación que refuerza lo argumentado y asumido previamente por L. No ocurre lo mismo en el caso de (3). La imposibilidad de la reformulación introducida por en efecto a cargo del mismo L (9) pone en evidencia que en (3) la relación causal entre aumento de servicios y no pago de expensas no solo no es asumida por L (y ello como consecuencia de que la enunciación se muestra como desencadenada por discursos ajenos que $\lambda$ no puede confirmar), sino que ella no constituye, como sí ocurre en (5), el objeto declarado de

10. Análogamente, Bermúdez $(2016,50)$ propone que la aportación modal del condicional de rumor es la renuncia por parte del hablante "a hacerse cargo de la veracidad de la información expresada, al mismo tiempo que no la pone en duda". 
la enunciación. Dicho de otro modo, por la presencia del Pdv evidencial plasmado en el condicional, (3) evoca una parte y solo una parte de las argumentaciones evocadas por (5). Análogamente, si (10) y (11) son posibles, el contraste entre (12) y (13) patentiza la restricción que, respecto de (12), el Pdv evidencial introduce en el significado de (13).

10. Murió Michael Jackson. El mundo está conmovido.

11. Habría muerto Michael Jackson. El mundo está conmovido.

12. Murió Michael Jackson. Un infarto acabó con la vida del rey del pop.

13. *Habría muerto Michael Jackson. Un infarto acabó con la vida del rey del pop.

Consideremos finalmente (4). Como en (3) y (11), el Pdv evidencial vehiculizado, en el caso de (4), por el futuro tendré también es citativo, ${ }^{11}$ pero sus instrucciones instan a recuperar otro tipo de marco de discurso citativo previo, a saber:

[Dicen $\mathrm{X}_{\text {(tener carencias/dificultades PLT no ser feliz) }}$ PLT admito $(\lambda)$ que $\mathrm{X}$ es posible] en el que la representación discursiva de las voces evocadas (las de las amigas, la de la madre, u otras personas que sostienen o pudieron haber sostenido que $\lambda$ no es feliz porque, por ejemplo, tiene dificultades o carencias) queda articulada con otra aserción sobre $\lambda: \lambda$ admite que $\mathrm{X}$ (eso que dicen) es posible. $\mathrm{Y}$ es este marco de discurso el que permite explicar el posicionamiento subjetivo de aceptación momentánea que queda configurado en la escena concesiva de (4). En efecto, inserto en una construcción adversativa [futuro..., pero...], no será este el Pdv que quedará asumido en la enunciación, sino el que continúa a pero (i. e., el relativo a tengo marido). Ello no obsta para que la enunciación de ese primer segmento quede representada como causada por un decir ajeno que L concede porque $\lambda$ lo admite como posible.

[como admito que es posible(eso que mi madre/mis amigas/otros dicen)], lo concedo (aunque el PdV que adoptaré es el referido a que tengo marido).

11. Según González Vázquez, "la lectura evidencial citativa [del futuro] estaría restringida a aquellos casos en los que no se puede adjudicar la fuente de información al interlocutor que acaba de mencionar explícitamente la proposición que recoge el futuro" (63). Es este, precisamente, el caso de (4). 
Este posicionamiento, que desde mi punto de vista no puede verse como derivado de una conjetura ni de una inferencia, ${ }^{12}$ constituye así la huella de la respuesta dialógica al marco de discurso citativo sobre el que se funda la enunciación:

[Dicen X PLT admito $(\lambda)$ X es posible] POR LO TANTO enunciación concesiva de $\mathrm{L}$

Nuevamente el contraste con el enunciado alternativo (14)

14. No soy feliz pero tengo marido.

permite ver que el presente soy en el primer segmento no obliga a buscar un marco de discurso previo referido a voces previas que $\lambda$ acepta como posibles. En efecto, y aunque L tampoco haga luego de ella el punto de su enunciación, la argumentación tener carencias o dificultades PLT no ser feliz se presenta en (14) como una suerte de confesión del propio L (i. e., L confiesa su tristeza o desventura asertando que $\lambda$ no es feliz).

En síntesis, estos pocos ejemplos han intentado demostrar cómo los PdV evidenciales plasmados en el enunciado contribuyen a la representación dialógica y polifónico-argumentativa de la causa de la enunciación, causa que no está determinada por el estatuto real de la fuente de información. Como afirma Mushin,

una mirada incluso superficial de los modos en que la gente utiliza la codificación evidencial indica que, aun en lenguas con sistemas evidenciales altamente gramaticalizados, el uso que los hablantes hacen de las formas evidenciales no refleja necesariamente el medio real a través del cual adquirieron la información. (53)

Tal como procuré mostrar, la causa de la enunciación debe hallarse en el marco de discurso previo en el que una cierta representación discursiva de las fuentes queda articulada con aserciones sobre $\lambda$ respecto de ellas. Esto es particularmente evidente en el caso de los Pdv citativos, en el que los diferentes marcos que sus instrucciones causales instan a recuperar construyen representaciones distintas del decir al que se alude: como un decir no probado (3), como un decir probablemente cierto (4) o como un decir incumplido o men-

12. Según la NGLE, el futuro que aparece en (4) constituiría una variante contextual del futuro de conjetura. Escandell Vidal también incluye los llamados usos concesivos del futuro en la categoría del futuro de conjetura, al que caracteriza como evidencial inferencial a partir de un proceso mental interno. 
tiroso, como, por ejemplo, en enunciados del tipo ¿Qué te pasó? iiAl final, no viniste el otro día!! Y es a partir de esa representación que se explica el posicionamiento subjetivo de aserción cautelosa, de concesión, de reproche, etc. que queda configurado en el enunciado.

\section{EL EDAP Y LOS PdV ALUSIVOS}

A diferencia de los Pdv evidenciales, que instan a recuperar un marco de discurso previo que se muestra como la causa de la enunciación en la que ellos se expresan, los Pdv alusivos no contienen instrucciones dialógico-causales. Se trata de modos de decir en los que se retoma, se transforma, se enmascara o se exhibe lo dicho en un acontecimiento discursivo anterior. Desde los más explícitos hasta los más velados, desde los más intencionales hasta los más involuntarios, los PdV alusivos funcionan a modo de recuerdo de discursos previos y habilitan, de ser reconocidos por el interpretante, el acceso a ellos. En efecto, al no constituir el objeto declarado de la enunciación, sino, más bien, un sentido agregado, estos Pdv pueden ser pasados por alto, pero, de no ser así, su enunciación permite el establecimiento de un vínculo de complicidad con el destinatario que reconoce esas remisiones como parte de la "memoria discursiva". Como afirma Authier-Revuz (1992), las alusiones permiten establecer un lazo de saber compartido, aunque solo toman cuerpo si se las reconoce: la "alusión depende totalmente del reconocimiento por parte del receptor de un «ya dicho» en otro lugar" (42). La autora agrega que las alusiones presentan un segundo "riesgo" y es que pueden ser identificadas aun cuando no hayan sido producidas conscientemente:

por supuesto, una alusión puede no ser reconocida; pero un segmento también puede ser reconocido e interpretado por el receptor como venido de otra parte, independientemente de toda intención del enunciador, para quien ese "ya dicho" no tendrá el estatus de una alusión intencional [...] y al que, en conflicto en ese punto con el receptor, podrá denegar toda realidad. $(1992,42)$

Por su parte, Moirand, que estudia los discursos de la ciencia en la prensa escrita, caracteriza las alusiones como índices de contextualización dialógica. La autora sostiene, en este sentido, que

la comprensión del sentido social de una serie de acontecimientos científicamente lejanos [...] reposa sobre la recurrencia de semas, de palabras 
o de construcciones sintácticas, que funcionan a modo de índices de contextualización dialógica y contribuyen al tejido de hilos interdiscursivos entre esos diferentes acontecimientos. (146)

En otras palabras, la recurrencia de ciertas configuraciones lingüísticas y discursivas habilita la emergencia de los PdV alusivos que, en tanto eco de acontecimientos enunciativos anteriores, permiten "poner al descubierto [...] el interdiscurso que allí se cobija” (Moirand, 160). Aquí me detendré en los PdV alusivos que se manifiestan a través de paralelismos morfológicos y sintácticos, de reformulaciones o de repeticiones de segmentos textuales, de distintas formas del silenciamiento y que, al evocar lo "ya dicho" en otro lugar, actualizan en el presente de la enunciación los sentidos de formulaciones anteriores.
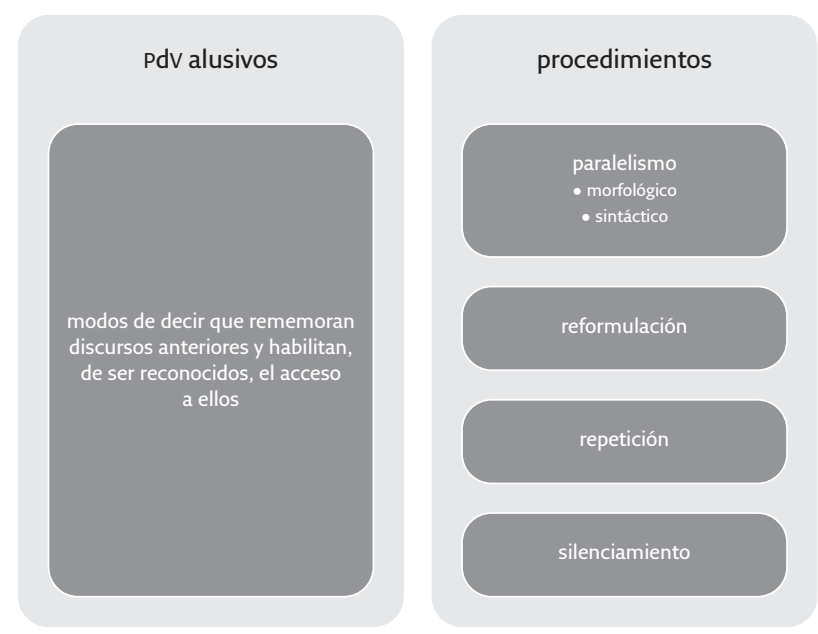

Tabla 2. Pdv alusivos y algunos procedimientos mediante los que se manifiestan y que permiten identificarlos

\subsection{PdV alusivos por paralelismo}

Consideremos, para comenzar, el caso de ciertas formas ya lexicalizadas, como cristileaks, en (15) o FIFAgate, en (16), en las que el primer elemento especifica la situación particular a la que se aplica la noción de 'información conflictiva que salta a la luz' asociada al segundo elemento: ${ }^{13}$

13. Agradezco esta precisión a uno de los revisores anónimos. 
15. "Cristileaks", los documentos de la ruta del dinero K que Cristina Kirchner intentó esconder [Titular] (TN 21 agosto 2016)

16. Después del FIFAgate: mejoran las condiciones de vigilancia de Burzaco en los Estados Unidos [Titular] (La Nación 12 febrero 2017)

Se trata, como se constata, de palabras construidas sobre la base de un paralelismo morfológico con otras, cuyo origen se remonta a otros discursos, y que permiten inscribir al enunciado en el que aparecen como elemento de una serie más amplia. A su vez, esa inscripción repercute en la semántica de las palabras así formadas, que se llenan de los sentidos que en esa serie han adquirido, al tiempo que permite dar cuenta, en los ejemplos (15)-(16), del posicionamiento crítico de L. Así, cristileaks, vocablo con el que se denominó a partir de agosto de 2016 el informe sobre la llamada "ruta del dinero K", alude por su forma misma a WikiLeaks, la organización fundada por J. Assange que publica filtraciones de informes anónimos y de documentos confidenciales con contenido sensible en materia de interés público. Fifagate, por su parte, permite caracterizar el enunciado que la contiene como un nudo más en la cadena de discursos referidos a otros gates: entre otros, el Watergate (el escándalo político que en 1972 llevó al entonces presidente norteamericano Nixon a renunciar a la primera magistratura), el Yomagate (el escándalo por narcotráfico en el que estuvo implicada, en 1991, Amira Yoma, secretaria de audiencias y cuñada del entonces presidente argentino Menem), el EREgate (el escándalo por corrupción política relacionado con prejubilaciones aparentemente fraudulentas).

Pero los paralelismos a través de los cuales pueden manifestarse los Pdv alusivos también pueden ser de orden sintáctico. Así, por ejemplo, las reminiscencias dialógicas que resuenan en las consignas Todos somos Nisman y Yo soy Nisman, mencionadas en el artículo periodístico de (17), habilitan la incorporación de esos enunciados en la red de discursos en apoyo a víctimas de atentados o en demanda del esclarecimiento de muertes violentas.

17. "Todos somos Nisman", un grito multitudinario [Titular] [...] Con duros cuestionamientos al gobierno nacional, lentamente, desde las 19.30, decenas de grupos de personas comenzaron a llegar a la histórica plaza. "Yo soy Nisman"; "Todos somos Nisman. Pedir justicia es defender la democracia", "Basta de mentiras", fueron algunas de las consignas que escribieron los manifestantes en carteles. ( $L a$ Nación 20 enero 2015) 


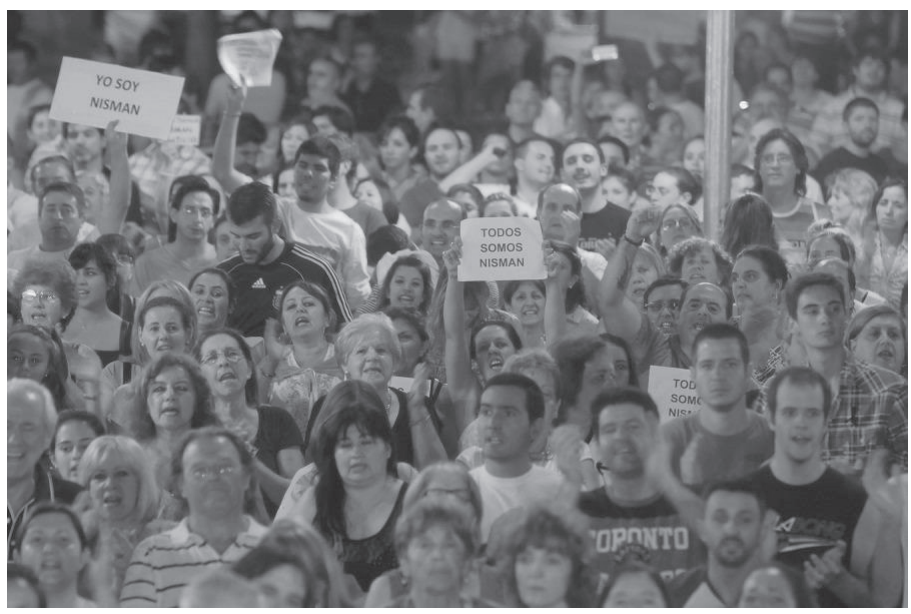

Foto de la marcha del 19/1/2015 en Buenos Aires

En efecto, en tanto Pdv alusivos, dichas consignas difundidas a través de las redes sociales y coreadas durante las marchas en reclamo por la dilucidación de la muerte del fiscal que denunció a la entonces presidenta de la Argentina por el pacto con Irán evocaban sus contemporáneas fe suis Charlie y sus variantes Nous sommes tous Charlie, fe suis Français et je n'ai pas peur, fe suis Charlie même pas peur. ${ }^{14}$ Como se recordará, estas últimas habían sido utilizadas durante las manifestaciones de apoyo, luego del atentado fundamentalista, el 7 de enero de 2015, contra el semanario satírico francés Charlie Hebdo.

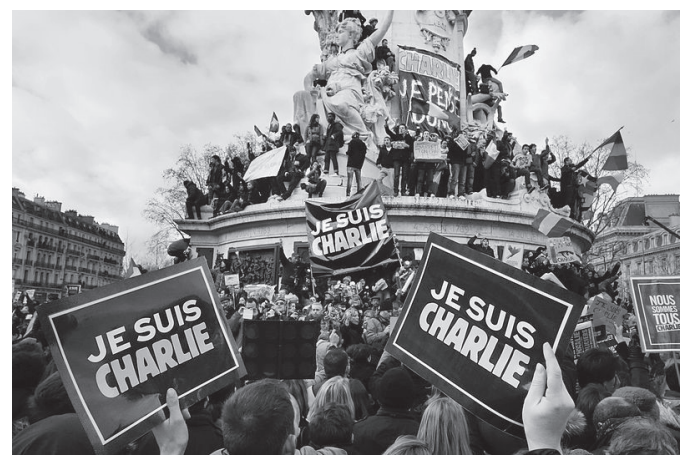

Foto de la marcha del 11/1/2015 en París

14. Yo soy Charlie, Todos somos Charlie, Yo soy francés y no tengo miedo, Yo soy Charlie y no me asustás. 
A su vez, fe suis Charlie y sus semejantes rememoraban el eslogan Ce soir nous sommes tous Américains, ${ }^{15}$ que se difundió luego del ataque a las Torres Gemelas, el 11 de septiembre de 2001.

Debe señalarse asimismo que, por su forma sintáctica (una estructura copulativa) y por su brevedad, todas estas consignas remiten a otras frases célebres -y que, por lo tanto, también contribuyen a su sentido-, como las entonadas durante el Mayo francés en apoyo a Daniel Cohn-Bendit, entonces portavoz del movimiento estudiantil, por los ataques sufridos contra sus orígenes familiares (Nous sommes tous "indésirables" y Nous sommes tous des fuifs et des Allemands) ${ }_{16}^{16} \mathrm{o}$ la pronunciada por J. F. Kennedy en junio de 1963 en ocasión de su visita a Berlín oeste bloqueado desde hacía quince años (Ich bin ein Berliner). ${ }^{17}$ Como afirma Bajtín, la palabra está habitada por la voz del otro y se carga de los sentidos que ha tenido en los diferentes géneros y textos en los que ha vivido.

Ahora bien, como anticipé, los Pdv alusivos pueden pasar inadvertidos para algunos interpretantes. Es lo que ocurrió con el siguiente ejemplo, tomado de una de las tapas de la revista Barcelona, en el que por paralelismo sintáctico se retoma y se transforma un modo de decir producido con anterioridad.

18. El bumor causó doce nuevas muertes [Titular] (Barcelona 8 enero 2015)

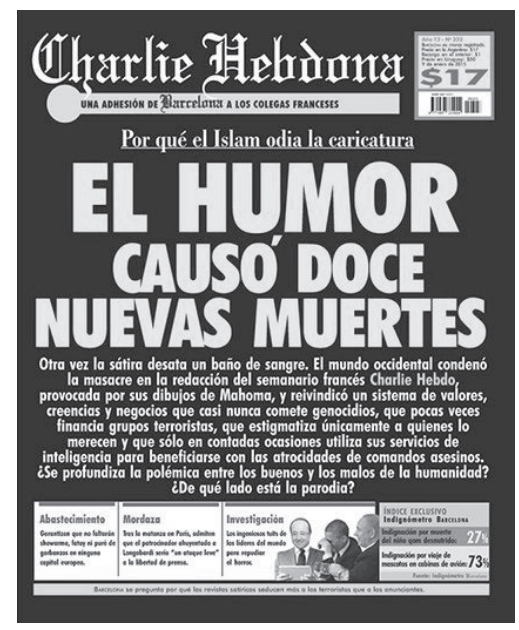

15. Esta noche, todos somos norteamericanos.

16. Todos somos "indeseables" y Todos somos judíos y alemanes. Agradezco a uno de los revisores anónimos el haberme hecho notar que es posible que la lexicalización provenga del contexto político del 68 y que después se haya reactivado en distintos discursos, como en el eslogan Todos somos Marcos del discurso zapatista de los 90.

17. Yo soy berlinés. 
Publicado el 8 de enero de 2015, el titular -una construcción causativa lexicalizada como forma para representar eventos negativos producidos por entidades no humanas y no volitivas- refiere sin dudas al asesinato, el día anterior, de doce miembros del equipo editorial de Charlie Hebdo por parte de un grupo de extremistas islámicos. Guiada por el propio género de la revista (una revista de humor satírico), una primera interpretación lleva a leer en dicha construcción una ironía: en términos de Ducrot, podría decirse que L pone en escena un Pdv absurdo del que se distancia y ello en la medida en que el humor no puede equipararse con, por ejemplo, las fuerzas de naturaleza que causan estragos. Pero los efectos de sentido de (18) no se acaban necesariamente allí, ya que el titular vehiculiza un Pdv alusivo por paralelismo sintáctico. Reconocida solo por algunos lectores, ${ }^{18}$ la estructura sintáctica de (18) reenvía a la de otro titular, perteneciente esta vez al discurso periodístico "serio", en el que se atribuye a otra entidad abstracta (la crisis), y no a sus verdaderos responsables (efectivos de la Policía Bonaerense), el asesinato, el día previo, de los piqueteros Kosteki y Santillán:

19. La crisis causó 2 nuevas muertes [Titular] (Clarín 27 junio 2002)

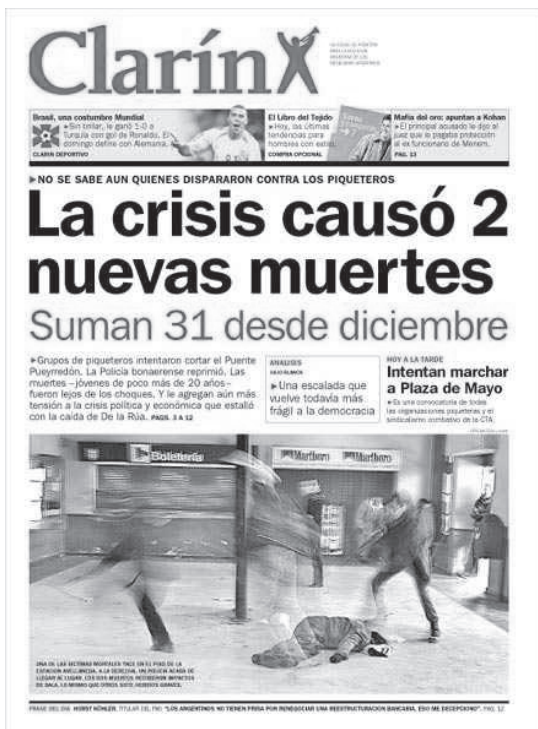

18. Agradezco este ejemplo a Adrián Martínez Levy, quien, por su condición de mexicano, no había reconocido el Pdv alusivo que allí se presenta. Tampoco lo percibieron algunos de los informantes argentinos a quienes pregunté al respecto. 
Espaciadas por casi 13 años, ambas enunciaciones muestran, sin embargo, una clara relación dialógica, en la que la segunda replica sintácticamente el modo de decir de la primera: además de la estructura causativa y de la mencionada atribución de la responsabilidad a un sujeto sintáctico abstracto (el bumor / la crisis), ambos titulares reiteran el sintagma nuevas muertes precedido de un numeral (doce /2). El titular de Barcelona no se limita así a la ironía que critica de manera punzante la intolerancia religiosa, sino que el Pdv alusivo por paralelismo sintáctico permite reconocer un sentido añadido de cuestionamiento a la supuesta seriedad informativa del diario Clarín. En otras palabras, detrás del modo de decir de (18), se alude de manera encubierta al modo de decir litótico de Clarín (19), el que queda transformado así en el segundo blanco del escarnio crítico de la revista quincenal argentina.

En suma, asociados a ciertas configuraciones morfológicas y sintácticas, los Pdv alusivos contienen reminiscencias dialógicas que señalan la presencia no marcada del discurso "otro" y establecen, de ser reconocidos, un lazo de complicidad entre locutor y destinatarios en tanto miembros de la misma comunidad que comparten el conocimiento de aquello a lo que se alude.

\subsection{PdV alusivos por reformulación y por repetición}

Se trata, en este caso, de Pdv que, a través de reformulaciones parafrásticas diversas o de repeticiones léxicas, evocan encadenamientos argumentativos que recurren en la memoria discursiva. Considérense, a modo de ejemplo, los siguientes fragmentos: (20) forma parte del editorial del 5 de abril de 1976 de la revista Para Ti; (21), de un discurso pronunciado por el entonces presidente Néstor Kirchner en marzo de 2006.

20. Llamemos las cosas por su nombre [Titular]

"Hay que salvar las instituciones". Las mujeres oíamos esa frase y no sabíamos exactamente qué pensar. [...]. Pero, ¿qué sucedía mientras tanto? Estallaban las bombas, aparecían cadáveres por todas partes, se cometían crímenes impunemente, el peso perdía aceleradamente su valor. "Salvar las instituciones". ¿Para qué? ¿̨Para que todos los días nos anunciaran que estábamos cayendo más hondo, bundiéndonos más en la desesperación, en la desidia, en el odio? (Para Ti 5 abril 1976)

21. Nosotros, de la mejor buena fe, le hemos tratado de explicar al sector, porque así como no queremos patria de esto, patria de aquello y 
respetamos y respeto a los productores que vi trabajando en muchísimos lados, no queremos la "patria ganadera" que quieren algunos dirigentes del campo. (Discurso de Néstor Kirchner 30 marzo 2006)

Publicado a menos de un mes del golpe de Estado que puso en marcha la dictadura más terrible y sangrienta de la Argentina, el editorial (20) reformula uno de los discursos argumentativos que se repitieron y parafrasearon en diversos artículos y editoriales difundidos por la prensa escrita en apoyo a los distintos golpes militares producidos a partir de 1930 (Vitale). Me refiero a la argumentación instituciones democráticas PLT caída al abismo, que, presentada como perteneciente a la opinión general de la doxa y, por lo tanto, como evidente e indiscutida, aparece evocada en (20) a través de la asociación semántica entre el sintagma verbal salvar las instituciones y los predicados fuertemente negativos caer en lo más hondo y hundirnos en la desesperación, en la desidia y en el odio.

Según señala Vitale,$^{19}$ esta argumentación ya había aparecido, con distintas formulaciones, en editoriales de la revista Atlántida (1930), de la revista Cabildo (1943) y del diario Clarín (1955, 1966 y 1976), por lo que, al hacer resonar una vez más esos discursos previos en la actualidad de la enunciación, el PdV alusivo desplegado en (20) genera un efecto de evidencia tendiente a crear consenso en torno a la representación de los hechos que sugiere. Así, y al igual que otras argumentaciones también recurrentemente reformuladas, como la que se expresó bajo la forma sociedad enferma PLT intervención militar, este tipo de Pdv alusivos orientaron, en la dimensión pathémica, "a despertar en el auditorio pasiones como el miedo o la angustia ante los gobiernos derrocados y alivio y tranquilidad ante los golpes de Estado" (Vitale 8).

Considérese ahora el caso de (21), en el que los segmentos patria de esto, patria de aquello, patria ganadera expresan Pdv alusivos por repetición léxica. En efecto, utilizado por lo menos desde hace 50 años por varios sectores de la sociedad argentina, el sintagma patria +adjetivo recurrió bajo distintas formas: $p a$ tria contratista, patria financiera, patria privatista, patria ganadera. Si bien en algunas ocasiones también se lo utilizó para la autodefinición y, por lo tanto,

19. Vitale acuña la denominación memoria retórico-argumental para caracterizar el "retorno, transformación u olvido, en una serie discursiva, de estrategias persuasivas que tienen la función de generar la adhesión a favor de una tesis" (2). 
positivamente, ${ }^{20}$ el sintagma patria+adjetivo alude en su repetición en la red discursiva a concepciones político-económicas contrarias a L, por lo que está cargado de un claro sentido despectivo y denigratorio. En otras palabras, el sintagma evoca en la memoria discursiva la argumentación patria+adjetivo PLT reprobación. De hecho, y tal como lo prueba (23), es este el sentido que se actualiza en patria montonera en (22), sintagma con el que, unos días después del discurso citado en (21), uno de los dirigentes ganaderos caracterizó la política económica de veda a la exportación de carnes propiciada por el gobierno de Kirchner:

22. El ministro se refirió a la frase dicha ayer por el titular de la Confederación de Asociaciones Rurales de la Tercera Zona (CARTEZ) quien increpó al presidente diciendo "no aguantamos la presión de la patria montonera". (Infobae 9 abril 2006)

23. "En boca de ese sector, lo que se traduce cuando dice patria montonera, es patria subversiva...". (Rosario/12, 26 abril 2006)

En definitiva, y al igual que en el caso de las reformulaciones parafrásticas, los PdV alusivos por repetición de elementos léxicos presentan el discurso argumentativo que los sustenta como evidentes e incuestionables. Y ese efecto de evidencia, que permite el establecimiento del lazo de complicidad entre locutor y destinatarios, no es más que el resultado de las resonancias dialógicas que se entretejen en su sentido.

\subsection{PdV alusivos por silenciamiento}

En este último apartado, me ocuparé de distintas formas de silenciamiento que, apoyadas sobre algún elemento semejante explícito, evocan PdV alusivos. En efecto, para que este tipo de Pdv pueda emerger y ser reconocido resulta imperioso que lo aludido por silenciamiento guarde alguna relación de semejanza o similitud con algún otro elemento necesariamente explícito en el texto. Así ocurre en (24) y (25):

24. Hoy estaba leyendo los resultados de las elecciones en España y leía que en las dos principales ciudades españolas, en Barcelona y en Ma-

20. Por ejemplo, en algunos cánticos de la agrupación Montoneros ("Vamos a hacer la Patria peronista, vamos a hacerla montonera y socialista"). 
drid, habían ganado dos mujeres. En Barcelona, una activista social y, en Madrid, está a punto casi de ganar parece ser una exjueza de 71 años. Sí, en España parece que se jubilan un poquito antes que aqui en la Argentina. (Discurso de Cristina Kirchner 25 mayo 2015)

25. ¿Y saben qué? No nos vamos a enojar. El odio se lo dejamos a ellos, el amor es nuestro, que ellos odien, el amor es nuestro. [...] ¿Saben qué? Y nos quedamos con el canto, nos quedamos con la alegría, nos quedamos con ese grito de "viva la Patria". Y a ellos, a ellos les dejamos el silencio. Siempre les gustó el silencio, a ellos les dejamos el silencio, que es o porque no tienen nada que decir o porque realmente no pueden decir lo que piensan. (Discurso de Cristina Kirchner 11 febrero 2015)

En términos de la teoría polifónica, el L de (24), aquí homologado con la entonces presidenta Kirchner, pone en escena un punto de vista irónico, señalado por el diminutivo un poquito antes, del que claramente se distancia. De hecho, el segmento es enunciado con una sonrisa y una actitud burlonas. Pero los efectos de sentido de ese tramo no se agotan allí: su enunciación muestra además un Pdv alusivo que, mediante el sí con el que L parece contestar a lo que el auditorio estaría pensando o diciéndose, establece un vínculo de complicidad entre ambos. Se trata de la alusión por silenciamiento al caso del juez de la Corte Suprema argentina Carlos Fayt, en ese entonces de 96 años y quien, a pesar de los intentos del gobierno por lograr su jubilación, siguió en su cargo hasta el último día de la presidencia de Cristina Kirchner. Y así lo pusieron en evidencia los comentarios periodísticos publicados al día siguiente, como lo confirman (26) y (27):

26. Reservó una parte para referirse al juez de la Corte Suprema Carlos Fayt, al que el kirchnerismo busca eyectar. (Clarín 26 mayo 2015)

27. No faltaron las alusiones al juez de la Corte Suprema Carlos Fayt cuando mencionó a una candidata de Podemos en Madrid, que "es una ex jueza de 71 años (sí, en España parece que se jubilan antes)”. (Página/12, 26 mayo 2015)

Como se advierte, la alusión fue exitosa: la presencia explícita del lexema exjueza (i. e., jueza jubilada) y la mención de la edad, 71 años, en la enunciación presidencial necesariamente evocaron por similitud los elementos silenciados: juez Fayt (i. e., juez en ejercicio) y 96 años. De este modo, y mediante el pasaje de la argumentación normativa más de 70 años PLT jubilación a la transgresiva 
más de 70 años SE no jubilación, el enunciado irónico tuvo como blanco el discurso del contradestinatario, es decir, el de aquellos que afirmaban que un juez de 96 años no tenía por qué jubilarse.

Otro tanto ocurre en (25), esta vez inscripto en un discurso de tono serio, en el que el sustantivo silencio atribuido al contradestinatario (obsérvese al respecto la recurrencia del pronombre ellos -a quienes también se atribuye el odio, el agravio, la infamia y la calumnia- opuesto al nosotros como colectivo de identificación) permite establecer un vínculo de semejanza con lo no dicho: la marcha del silencio en homenaje al fiscal Nisman convocada para el 18 de febrero de ese mismo año. Sin nombrarlos explícitamente pero claramente aludidos, sus convocantes se constituyeron así en el objeto de la crítica presidencial: Siempre les gustó el silencio, a ellos les dejamos el silencio, que es o porque no tienen nada que decir o porque realmente no pueden decir lo que piensan. Nuevamente, así lo destacaron las notas periodísticas posteriores:

28. Allí, luego de decir que "los necesitaba", apuntó contra quienes "intentan tergiversar cosas" y quieren "que nos enojemos". (Infobae 11 febrero 2015)

29. El punto más fuerte de su discurso bizo referencia a la marcha del silencio en homenaje al fiscal Alberto Nisman. Cristina dijo tajante: "Nos quedamos con el canto, con la alegría, a ellos, a ellos les dejamos el silencio. Siempre les gustó el silencio; ¿saben por qué?”, expresó. [...] La frase fue una contundente respuesta a la convocatoria que más preocupa al oficialismo, que se llevará a cabo el próximo miércoles. (La Nación 12 febrero 2015)

Así, aunque de carácter irónico -(24) - y con fuertes señales de irritación -(25)-, ambos fragmentos presentan PdV alusivos que, sin decir explícitamente a quién o a qué apuntan, permiten no solo dar cuenta del posicionamiento crítico de L, sino también evocar la figura del contradestinatario indirecto oculto en complejos ilocucionarios (García Negroni 2016c), en los que a la aserción dirigida a los prodestinatarios se agrega la desautorización, descalificación o refutación de la voz del otro negativo.

En suma, cimentados sobre algún elemento léxico explícito que promueve la analogía, los Pdv alusivos por silenciamiento funcionan a modo de recuerdo velado de discursos del otro negativo presentes en la memoria discursiva con el fin de descalificarlos y, al hacerlo, establecen un lazo de complicidad intersubjetiva entre L y sus destinatarios positivos. 


\section{A MODO DE CIERRE}

En este trabajo, he buscado ahondar en la construcción del EDAP, cuyos pilares básicos pueden resumirse como sigue: a) no existe elemento de la significación cuyo carácter sea puramente objetivo, b) el sentido de toda entidad lingüística está constituido por los encadenamientos argumentativos -normativos o transgresivos- que esa entidad evoca, c) los Pdv subjetivos que se expresan en la enunciación no necesariamente deben ser atribuidos a la misma figura discursiva y d) el discurso y el sujeto están constitutivamente atravesados por la presencia del otro. Para ello, me centré en el estudio de los Pdv evidenciales y de los Pdv alusivos con el fin de mostrar cómo unos y otros contribuyen al sentido del discurso y a la configuración dialógica de la (inter)subjetividad.

Caractericé, en primer lugar, los Pdv evidenciales como Pdv que contienen instrucciones dialógico-causales que obligan a interpretar la enunciación que los incluye como causada por un marco de discurso previo en el que una cierta representación discursiva de las fuentes (percepciones, indicios o voces citadas o prefiguradas) queda articulada normativa o transgresivamente con aserciones sobre $\lambda$ respecto de ellas. Ese marco de discurso, que se presenta como la causa de la enunciación, es el que explica los distintos posicionamientos subjetivos de respuesta que pueden manifestarse en el enunciado (aserciones fuertemente comprometidas, aserciones cautelosas y con reservas, concesiones, reproches, etc.).

Me detuve luego en el estudio de los Pdv alusivos. Se trata, en este caso, de modos de decir mediante los cuales - por paralelismo, reformulación, repetición, silenciamiento, etc.- se retoma, se reformula, se encubre o se exhibe lo "ya dicho" en un acontecimiento discursivo anterior. Con carácter de eco de discursos ajenos, estos Pdv permiten poner de manifiesto la relación del enunciado con otros enunciados en la cadena discursiva y mostrar así que en toda producción lingüística circulan formulaciones anteriores frente a las cuales, consciente o inconscientemente, quedan constituidos posicionamientos subjetivos. Señalé, finalmente, que, en tanto formas de la heterogeneidad mostrada no marcada, los PdV alusivos pueden pasar inadvertidos. Sin embargo, si la alusión es reconocida, el Pdv permite establecer un pacto de complicidad intersubjetiva entre L y sus destinatarios, que reconocen la presencia no marcada del discurso "otro" como parte de la "memoria discursiva". 


\section{OBRAS CITADAS}

Aikhenvald, Alexandra. Evidentiality. Oxford: Oxford UP, 2004.

Authier-Revuz, Jacqueline. "Hétérogénéité(s) énonciative(s)". Langages 73 (1984): 98-111.

Authier-Revuz, Jacqueline. "Repères dans le champ du discours rapporté". L'Information grammaticale 55 (1992): 38-42.

Bajtín, Mijail. Estética de la creación verbal. Buenos Aires: Siglo XXI, 1982.

Bermúdez, Fernando. "Los tiempos verbales como marcadores evidenciales: el caso del pretérito perfecto compuesto". Estudios Filológicos 40 (2005): $165-88$.

Bermúdez, Fernando. "Rumores y otros malos hábitos: el condicional evidencial en español". Cuadernos de Lingüística de El Colegio de México 3/2 (2016): 35-69.

Carel, Marion. "Note sur l'abduction". Travaux de linguistique 49 (2004): 95 113.

Carel, Marion, y Oswald Ducrot. La semántica argumentativa. Buenos Aires: Colihue, 2005.

Cornillie, Bert. Evidentiality and Epistemic Modality in Spanish (Semi-)Auxiliaries: A Cognitive-Functional Approach. Berlin: Mouton de Gruyter, 2007.

Cornillie, Bert. "Las lecturas evidenciales de los verbos (semi)auxiliares en español”. La evidencialidad en español: teoría y descripción. Eds. Ramón González Ruiz, Dámaso Izquierdo Alegría y Óscar Loureda Lamas. Madrid: Iberoamericana/Frankfurt am Main: Vervuert, 2016. 227-49.

Courtine, Jean-Jacques. "Analyse du discours politique (le discours communiste adressé aux chrétiens)". Langages 62 (1981): 9-128.

Dendale, Patrick. "Devoir épistémique, marqueur modal ou évidentiel?". Langue française 102 (1994): 24-40.

Dendale, Patrick, y Danielle Coltier. "Point de vue et évidentialité". Cabiers de praxématique 41 (2003): 105-30.

Ducrot, Oswald. Le Dire et le dit. Paris: Minuit, 1984.

Ducrot, Oswald. "Sentido y argumentación". Homenaje a Oswald Ducrot. Eds. Elvira Arnoux y María Marta García Negroni. Buenos Aires: Eudeba, 2004. 359-70.

Escandell Vidal, María Victoria. "Futuro y evidencialidad". Anuario de Lingüística Hispánica 26 (2010): 9-34.

García Negroni, María Marta. "Polifonía, evidencialidad y descalificación del discurso ajeno: acerca del significado evidencial de la negación metadis- 
cursiva y de los marcadores de descalificación”. Letras de Hoje 51.1 (2016a): 7-16.

García Negroni, María Marta. "Polifonía, evidencialidad citativa y tiempos verbales: acerca de los usos citativos del futuro morfológico y del futuro perifrástico". La evidencialidad en español: teoría y descripción. Eds. Ramón González Ruiz, Dámaso Izquierdo Alegría y Óscar Loureda Lamas. Madrid: Iberoamericana/Frankfurt am Main: Vervuert, 2016b. 279-302.

García Negroni, María Marta. "Discurso político, contradestinación indirecta y puntos de vista evidenciales: la multidestinación en el discurso político revisitada". Revista ALED 16.1 (2016c): 37-59.

García Negroni, María Marta, y Manuel Libenson. "Argumentación, evidencialidad y marcadores del discurso: el caso de por lo visto". Tópicos del Seminario 35 (2016): 51-75.

González Vázquez, Mercedes. "La naturaleza y función de la evidencialidad en español". La evidencialidad en español: teoría y descripción. Eds. Ramón González Ruiz, Dámaso Izquierdo Alegría y Óscar Loureda Lamas. Madrid: Iberoamericana/Frankfurt am Main: Vervuert, 2016. 49-74.

Kasim, Hanan. "Análisis de los valores evidenciales de las expresiones de probabilidad y posibilidad con poder, deber y tener que". Language Design 17 (2015): 85-102.

Kronning, Hans. "Le conditionnel épistémique: propriétés et fonctions discursives". Langue française 173 (2012): 83-97.

Kronning, Hans. "El condicional epistémico «de atribución» en francés, italiano y español: aspectos diafásicos, diatópicos y diacrónicos". Les Variations diasystématiques et leurs interdépendances dans les langues romanes. Eds. Kirsten Jeppesen Kragh y Jan Lindschouw. Estrasburgo: Éditions de linguistique et de philologie, 2015. 507-18.

Leonetti, Manuel, y María Victoria Escandell Vidal. "On the Quotative Readings of Spanish Imperfecto”. Cuadernos de Lingüistica 10 (2003): 135-54.

Moirand, Sophie. "Les indices dialogiques de contextualisation dans la presse ordinaire". Cabiers de praxématique 33 (1999): 145-84.

Mushin, Ileana. Evidentiality and Epistemological Stance. Amsterdam/Filadelfia: Benjamins, 2001.

NGLE: Real Academia Española, y Asociación de Academias de la Lengua Española. Nueva gramática de la lengua española. Madrid: Espasa, 2009.

Reyes, Graciela. Los procedimientos de cita: citas encubiertas y ecos. Madrid: Arco Libros, 1994. 
Rodríguez Ramalle, María Teresa. "Sobre marcadores y su relación con la modalidad evidencial". Marcadores del discurso: perspectivas y contrastes. Ed. María Marta García Negroni. Buenos Aires: Santiago Arcos, 2014. 233-50.

Vatrican, Axelle. "Usos y valores modales del condicional en español”. Archivum 64 (2014): 239-74.

Vitale, María Alejandra. "La dimensión argumentativa de las memorias discursivas: el caso de los discursos golpistas de la prensa escrita argentina (1930-1976)". Forma y Función 22.1 (2009): 1-13. 5 de febrero de 2017. $<$ www.revistas.unal.edu.co/index.php/formayfuncion/article/view/20547 /36044>.

Willett, Thomas. "A Cross-Linguistic Survey of the Grammaticalization of Evidentiality". Studies in Language 2 (1988): 51-97. 